ARTICLE

https://doi.org/10.1057/s41599-019-0334-6

\title{
The spatial competition between containerised rail and sea transport in Eurasia
}

\author{
Mengqiu Lu', Yu Chen ${ }^{2 \star}$, Robin Morphet ${ }^{3}$, Yuqi Lu² \& Enkang $\mathrm{Li}^{2}$
}

\begin{abstract}
The competition in space between rail and sea transport is of great significance to the integration of Eurasia. This paper proposes a land and sea transport spatial balance model for container transport, which can extract a partition line on which transport costs by rail and sea are equal given a destination. Four scenarios are discussed to analyse the effects of different factors on the model. Then the model is empirically tested on current rail and sea transport networks to identify the transport competition pattern in Eurasia. The location of destinations, the freight costs, and time costs are the three main factors affecting the model. Among them, time costs are determined by the value of a container and its contents, the interest rate, and by time differences between land and sea transport. The case study shows that Eurasia forms a transport competition pattern with a land area to sea area ratio of about 1:2; this ratio, however, changes to 1:1 when time costs are considered. Further, the land and sea transport balance lines are consistent with the theories of geopolitics, which indicate that the same processes may exist in the spatial pattern of geo-economics and geopolitics in Eurasia. According to the balance lines, we get a spatial partition, dividing Eurasia into the land transport preferred area, the land-sea transport indifference area, and the sea transport preferred area. The paper brings a new perspective to the exploration of geopolitical economic spatial patterns of Eurasia and provides a practical geographic theory as an analytic basis for the implementation of the Belt and Road Initiative.
\end{abstract}

\footnotetext{
${ }^{1}$ School of International Economics and Trade, Nanjing University of Finance and Economics, Nanjing 210023, China. ${ }^{2}$ School of Geography, Nanjing Normal University, Nanjing 210023, China. ${ }^{3}$ Centre of Advanced Spatial Analysis, University College London, London W1T 4TJ, UK. *email: chenyu@lreis.ac.cn
} 


\section{Introduction}

ue to the continuous development of maritime transport and its reducing costs, intercontinental containerised transport has been mainly completed over maritime routes during the past century. The three largest economies in the world, the European Union (GDP \$18 trillion), North America (US GDP about \$17 trillion), and East Asia (GDP \$16 trillion, of which China's GDP is $\$ 11$ trillion), account for about three quarters of the world's global economy and, for trading purposes, are connected by the Atlantic route (about $8000 \mathrm{~km}$ ), the Pacific route (about 12,000 km), and the Pacific-Indian Ocean-Mediterranean route (about $18,000 \mathrm{~km}$ ). However, the European Union and East Asia can also trade through rail transport corridors (about 11,000 km). According to the United Nations Economic Commission for Europe report of 2018, the total volume of containers imported and exported between China and EU by sea and land transport was $62 \%$ and $7 \%$, respectively (UNECE, 2018). This implies a large market share gap between containerised rail transport and maritime transport in Eurasia. Thus, a question arises: Should rail transport really be so discounted?

Rail and sea modes compete for container transport. Although the freight cost per kilometre advantage of shipping is unmatched by rail transport, normally its time cost is higher. In 2011, China opened the first China Railway Express (CRE) line from Chongqing, China to Duisburg, German, which takes about 15 days. As of December 2017, there were a total of 6235 trains and 57 CRE train lines all of which can complete transportation within half a month (Xinhuanet, 2017), and the services of CRE are becoming more regular. In contrast, the sea time from China's coastal ports to European ports is generally 30-45 days (depending on the shipping schedules and different shipping companies, such as MSC, Cosco, OOCL, CMA, and COCL). In the past, the lack of a public container transport service by railway and the good management of maritime transport, meant that rail could not compete effectively shipping. Now, however, its time-saving can be of significance.

Sea routes have dominated the market for a long time, and a huge gap in economic development has emerged between nonlittoral and littoral regions on the Eurasian continent. This imbalance needs to be overcome through the further development of land transport. The construction of land transport corridors determines the economic growth of non-littoral areas and supports the integration process of Eurasia. The Belt and Road Initiative of China (BRI), aimed at promoting integrated development in Eurasia, was formally announced by China's government in 2015 (Liu and Dunford, 2016; Liu et al., 2018; Wang, 2016; Ferdinand, 2016; Swaine, 2015; National Development and Reform Commission Ministry of Foreign Affairs Ministry of Commerce of China, 2015). The "Belt" mainly represents landbased transport and is called the 'Silk Road Economic Belt'; the Road represents maritime-based transport and is called the ' 21 st Century Maritime Silk Road'. It is clear that the "Road" has already passed the test of economic viability, but it remains to be seen whether the 'Belt' can similarly establish itself. Although bulk transport may also influence the transport pattern in Eurasia and elsewhere, we concentrate on container transport in this paper because of its high value to weight ratio and its significance as an important economic component under the BRI in Eurasia.

Based on its time cost competitiveness and the requirements of integrated development, rail transport routes cannot be ignored. For different locations of origins and destinations, the cost differential between rail and sea transport varies. In this paper, we address this comparative problem from the spatial perspective of transport geography. Put simply, we ask, where are the areas most suitable for rail transport of containers compared to those most suitable for shipping? In addition, knowing that the competitive pattern of rail and sea transport in Eurasia has a practical significance for the implementation of BRI, which factors influence this relationship?

\section{Literature review and hypothesis}

Transport costs differ according to modes and the locations of origins and destinations, and these are key factors in spatial competition research and in location theories (Krugman, 1993; Scotchmer and Thisse, 1992; Hummels, 2007). However, studies of trade transport mostly discuss land and sea transport modes separately, and the maritime network and port geography are always popular issues in international trade studies because world trade is highly dependent on ocean transport. In the context of the Belt and Road Initiative, there are more mature achievements in maritime transport than in rail transport in Eurasia (Lee et al., 2018; Chen and Yang, 2018; Lam et al., 2018; Peng et al., 2018). Research on rail transport mainly focusses on accessibility, development of the CRE or statistical analysis of specific rail corridors (Wang et al., 2015, 2018; Islam et al., 2013; Rodemann and Templar, 2014; Jiang et al., 2018), with only a few comparisons between different transport modes (Hillman, 2018; Schramm and Zhang, 2018; Tsuji, 2009). These comparative studies affirm that railway routes will change trade patterns in Eurasia. While they mainly analyse the freight costs of different transport modes, most of these studies are based on statistical discussions of global averages or are limited to individual cities, without any discussion of competition in space.

Some researchers have realised that differential time cost is a significant competitive factor for different transport modes, however, they only list the costs of transport, transit times and distances between some specific cities separately (Mo et al., 2015; Wang et al., 2017; UNECE/UNESCAP, 2008). A possible way to make a synthetic comparison is through measuring time by money, which permits the addition of freight and time costs. Some studies focus on the money value of time in commodities transport. G Blauwens (Blauwens and Van de Voorde, 1988) got a result that $0.00848 \%$ times the value of the goods equated to a $1 \mathrm{~h}$ gain in time based on real data in Belgium. A world model was proposed based on studies of international maritime shipments, which took values of time as nearly \$100/TEU (20-foot equivalent unit) per day based on the loss of value of the resulting from late arrival (Tavasszy et al., 2011; UNECE, 2018). We do not know whether these studies are applicable to different areas or at different scales. In most cases, however, studies simply prefer to estimate the value of time by interest, that is, the time saved by rapid transport could represent a considerable amount of basic interest income on goods' values. In this way, time costs can be calculated consistently with other freight costs. For example, a container transports from Beijing to Tianjin port first and then ships to Rotterdam port in about 31 days in total when it arrives in Berlin. However, it takes only 15 days by the CRE from Beijing to Berlin. If we put $\$ 300 \times 10^{3}$ (the current average value of a 40 inch container's goods on the CRE) in the bank we get about $\$ 48$ per day in interest income (based on the average interest rate of Chinese banks). In this case, this can be expressed as a loss of $\$ 720$ when a container worth $\$ 30 \times 10^{3}$ spends half a month or longer at sea.

Based on the conclusion above, we propose our hypothesis using first an abstract representation of area and transportation. We conceptualise an area as a circle surrounded by water, with the circumference set as a sea route and the interior of the circle set as land transport (see Fig. 1). This article only discusses competition between rail and maritime transport, so the inland 


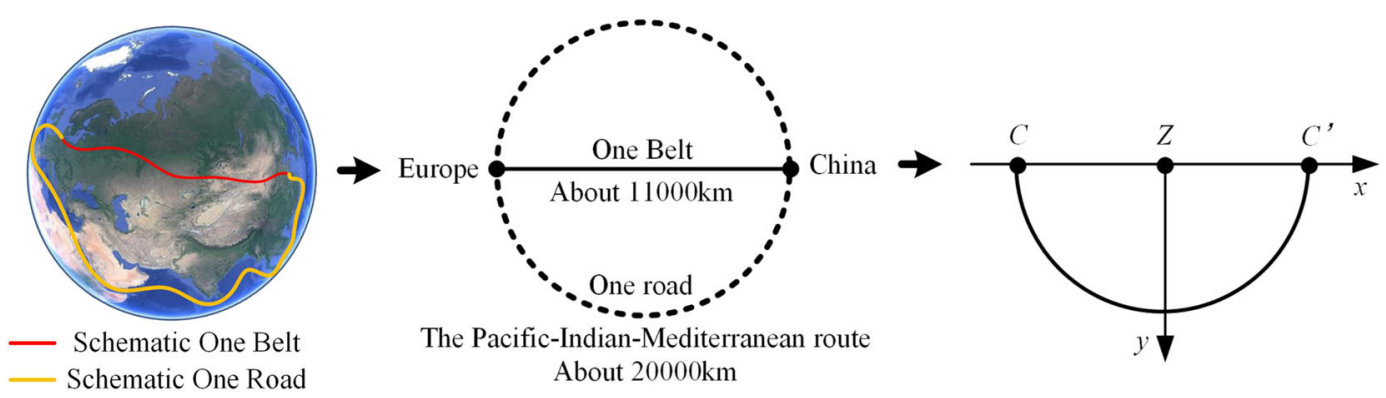

Fig. 1 Schematic of abstracted Eurasia

area inside the circle is assumed to be a homogeneous space covered by a railway network. As the circle is bilaterally symmetric across a transverse diameter, we need only take the lower half of the circle as our object of analysis. In reality, the length of the New Eurasian Land Bridge is about $11,000 \mathrm{~km}$ (from Lianyungang to Rotterdam) and the distance of the shipping route is about $20,000 \mathrm{~km}$ (the shipping distance from Lianyungang port to Rotterdam Port is about $19,900 \mathrm{~km}$ ). Here, if the diameter of the circle is $11,000 \mathrm{~km}$, the arc $\mathrm{CC}^{\prime}$ has a length of $17,300 \mathrm{~km}$. Therefore, the assumption above is not unrealistic. Based on the conceptualised semicircle, we propose a hypothesis of two transport modes: for any specific destination, there is a spatial balance line inside the semicircle, which consists of points, where the costs of transporting containers to the destination by rail and sea are equal. On the one side of the balance line, rail transport has a cost advantage and on the other side, shipping.

\section{Methodology: land and sea transport spatial balance model (LSTSB-model)}

Preparation of factors. In order to propose a theory of land-sea transport spatial balance, we construct a land and sea transport spatial balance model (LSTSB) based on the conceptualised semicircle above, which refers to the spatial expression of the balance lines. We could calculate not only railway transport but also road transport or mixed rail/road as the land transport in this model, so we term it land transport. However, in order to point out the specific comparative question between rail and sea transport in Eurasia, and the parameters for land transport are all set as railway transport in this paper.

The determination of the balance lines depends on the following three elements.

(1) Location of origin and destination: The location of any point, especially its distance to the sea, is a basic factor impacting the cost gap between rail and sea transport.

(2) Land and sea freight rates: The freight cost per kilometre. There are different freight costs for container transport by rail and sea. In general, shipping is the cheapest transport mode. At present, the Sino-European shipping freight rate is $\$ 0.15 /(\mathrm{FEU} \mathrm{km})$ (40-foot equivalent unit), while the current average price of rail transport is $\$ 0.6 /(\mathrm{FEU} \mathrm{km})$, which is approximately a four-times gap ${ }^{1}$.

(3) Land and sea transport time cost rates: The time cost per kilometre. If we simply express time costs as the interest income that would accumulate if the money equal to the value of a container was deposited in a bank, then it is possible to characterise transport time costs as a function of three items: the value of a container's goods, the transport time, and the basic interest rate of the bank. We can express this more specifically as follows:

a. The value of a container's goods: The higher the value of the goods, the more sensitive they are to time. b. The transport time: Generally, it takes more time to transport containers by sea than by rail because of the speed and distance. Cargo transport speed by rail is slightly faster than shipping and the length of land corridors is shorter than that of sea routes spanning Eurasia. The average speed of the current CRE is about $700 \mathrm{~km} /$ day $(29.2 \mathrm{~km} / \mathrm{h})$, and the average shipping speed is $660 \mathrm{~km} /$ day $(27.5 \mathrm{~km} / \mathrm{h})^{2}$.

c. The interest rate: The bank interest rates change over time and vary from country to country. For example, the current annual interest rate in China is about $6 \%(1.6 \% \text { /day })^{3}$.

Thus, the construction of the LSTSB Model requires three major inputs: the location of a certain point, the freight costs, and the time costs of rail and sea transport. Specifically, the value of container goods, transport time, and interest income are the three main derivative factors that need to be considered comprehensively.

Derivation of the formula. For destination $D$, there exists an origin $O$, such that the total costs of transport containers from $O$ to $D$ by land and sea are equal, which, considering freight costs and time costs together is given by

$$
w_{1} \times \text { dist }_{1}=w_{1} \times \text { dist }_{11}+w_{\mathrm{s}} \times \text { dist }_{\mathrm{s}}+w_{1} \times \text { dist }_{12}
$$

$w_{1}$ : the cost per kilometre of land transport, the sum of freight rate and time cost rate of land transport. $w_{s}$ : the cost per kilometre of sea transport, the sum of freight rate and time cost rate of sea transport. dist $t_{1}$ the distance from $O$ to $D$ on land transport corridor. dist 11 , dist ${ }_{\mathrm{s}}$ and dist $_{12}$ are the distance from $O$ to its nearest port 1 on land, the distance from port 1 to port2 by sea, and the distance of land leg from port 2 to $D$.

Here we take $\sigma=w_{\mathrm{s}} / w_{\mathrm{l}}$, then it can be simplified as

$$
\operatorname{dist}_{1}=\operatorname{dist}_{11}+\sigma \times \text { dist }_{s}+\text { dist }_{12}
$$

Based on Eq. (2), we assume that any point can always reach a target point by land and sea in the semicircle $Z: u^{2}+v^{2}=r^{2}$ (see Fig. 2), inside the semicircle is a homogeneous space covered by railway network as we mentioned above and each point on the coastal arc is a port. Then, we set the direct linear movement mode as land transport, and the movement via an arc between the nearest ports of origin and destination is considered as sea transport (it makes sure that the movement on land is the shortest among all joint land-sea transport possibilities in this case.). For point $D(a, b)$, point $O_{1}\left(x_{1}, y_{1}\right)$ can be reached via the straight line $O_{1} D$ (by land) or transport via $O_{1} P_{1}-\operatorname{arc} P_{1} Q-Q D$ (by sea). Specifically, $P_{1}, O_{1}$, and $Z$ are on a line to make sure it is the shortest distance to the coast. Similarly, point $\mathrm{O}_{2}\left(x_{2}, y_{2}\right)$ can reach $D$ in two ways, by a straight line $\mathrm{O}_{2} D$ or by $\mathrm{O}_{2} P_{2}-\operatorname{arcP}_{2} Q-$ QD. 


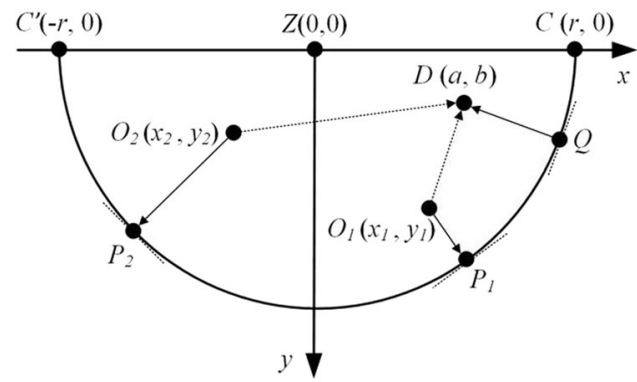

Fig. 2 Schematic of formula derivation

Then we can derive the balance line, consisting of balance points, from the following equation:

$$
\begin{gathered}
\sqrt{(x-a)^{2}+(y-b)^{2}}=\left(r-\sqrt{x^{2}+y^{2}}\right) \\
+\sigma \cdot r\left(\frac{\pi}{2}\left(1-\frac{x \cdot a}{\mid x \cdot a}\right)+\left(\frac{x \cdot a}{\mid x \cdot a}\right) \mid\left(\arctan \frac{b}{a}-\arctan \frac{y}{x}\right)\right) \\
+\left(r-\sqrt{a^{2}+b^{2}}\right) \\
\text { subject to }: x^{2}+y^{2} \leq r^{2}, y \geq 0,-\frac{\pi}{2} \leq \arctan \\
\frac{y}{x} \leq \frac{\pi}{2},-\frac{\pi}{2} \leq \arctan \frac{b}{a} \leq \frac{\pi}{2}
\end{gathered}
$$

Note: $|\arctan (y / x)|>|\arctan (b / a)|$ may be true or false, hence the absolute value of the difference is used.

Let $t_{1}$ (day) to be the total transport time from $C(r, 0)$ to $C^{\prime}(-r, 0)$ passing through $Z(0,0)$ by land, and similarly let $t_{\mathrm{s}}$ (day) be the total transport time via the $\operatorname{arcCC}$ going by sea. Let $k_{1}(\$ / \mathrm{km})$ represent the freight rate by land, and $k_{\mathrm{s}}(\$ / \mathrm{km})$ represent the freight rate by sea. The value of a container can be set as $m(\$)$, with $i$ (per day) representing the interest rate and $\varphi$ representing its sensitivity to time. Then, the interest per kilometre of the land mode is $\alpha$ $=\left(\varphi^{\star} t_{1}^{*} m^{\star} i\right) / 2 r$. Similarly, the interest per kilometre of the sea mode is $\beta=\left(\varphi^{\star} t_{\mathrm{s}}^{*} m^{\star} i\right) \pi r$ from which we may write, $\sigma=\left(k_{\mathrm{s}}+\beta\right) /\left(k_{1}+\alpha\right)$. Since the intent of this manuscript is to discuss a general competition pattern without considering different types of goods, this coefficient is set $\varphi$ to 1 .

Analysis of scenarios. Based on the equations above, we simulated four scenarios to examine the effects of the main factors on the model. Scenario 1 shows the balance lines of different destinations without interest costs calculated, and scenario 2 presents how the balance lines would change spatially when the ratio of freight rates between sea and land transport reduces from 1:4 to $1: 3,1: 2$ and 1:1. Scenario 3 then analyses the distribution of balance lines which are extracted from the model considering the time costs of transporting containers of different values. Lastly, we show the changes in balance lines when the speed of land transport increases in scenario 4.

Scenario 1: different locations-without considering time costs. In this scenario, we set radius $=1$ and $\sigma=\frac{\$ 0.15 /(\mathrm{FEU} \cdot \mathrm{km})}{\$ 0.6 /(\mathrm{FEU} \cdot \mathrm{km})}=1 / 4$ based on the current freight rates. Figure 3 shows the influence of destinations on transport balance lines, transport costs by land are always lower than by sea inside the shadowed area. The changes in the transport balance lines from coastal point $C$ to central point $O$ are clear.

(1) Point $C^{\prime}$ (reflecting the location of Europe): The balance line extends to the centre of Eurasia and the land transport advantage area is far away from the coastline. Finally, the transport balance line intersects the $x$-axis at point $(\pi / 8,0)$.

(2) Point $D$ (reflecting the location of the Middle East): The transport balance line extends to Central Eurasia, and the closer it is to the central area, the greater the expansion.
(3) Point $I$ (reflecting the location of South Asia): The land advantageous transport area is of a similar scale as that for point $D$, and the transport balance line also extends to the centre of Eurasia; the closer it is to the centre, the more the area expands.

(4) Point $H$ (reflecting the location of Central and Eastern Asia): Although $C^{\prime}, D$ and $I$ are in different places, they are all located along the coast. When the destination moves to the inland point $H$, a very large gap between land and sea transport advantage areas emerges. Land transport dominates a larger area than does shipping.

Results obtained from the model could provide suggestions for potential container transport preferred area, whether by rail or sea, to specific locations. Moreover, having been informed by these results, different countries or regions are better able to plan or designate more viable international transport routes. This would help explain their responses to China's "Belt and Road Initiative" from a transport geographic view. For example, for India (near the location of Point $I$ ), the sea transport preferred area is much larger than the rail transport area, and as such more attention must be paid to maritime trading. And also, they may consider rail routes building to connect the central area in Eurasia, like Russia, not China.

Figure 4 shows the ideal schema of the LSTSB Model in Scenario 1 , that is, there is a point $S(x, y)$ where its transport balance line passes point $S^{\prime}(-x, y)$, while the transport balance line of $S^{\prime}$ also meets $S$. $S$ and $S^{\prime}$ are symmetric and they can reach each other for the same cost by either land or sea transport, that is, they are each other's transport costs equivalent points. The solutions of points $S$ and $S^{\prime}$ are on the symmetric line $g(x, y)$ based on the $y$-axis. The formula of $g(x, y)$ is

$$
\begin{gathered}
2 \mid x-\left(2-2 \sqrt{x^{2}+y^{2}}\right)-\frac{1}{4}\left(\pi-2 \mid \arctan \frac{y}{x}\right)=0 \\
\text { subject to : } x^{2}+y^{2} \leq r^{2}, y \geq 0,-\frac{\pi}{2} \leq \arctan \frac{y}{x} \leq \frac{\pi}{2}
\end{gathered}
$$

Specifically, the transport balance line (the blue line) of $S(1-(8$ $-\pi) / 16,0)$ intersects $x$-axis at point $\left.S^{\prime}(-1-(8-\pi) / 16), 0\right)$, while the transport balance line of $S^{\prime}$ (the black line) also meets ss $S$. With $S$ and $S^{\prime}$ as the destination points, the land and sea transportation channels are constructed as a "dual-core structure" between Europe and China, dividing Eurasia into a land transport preferred area and a sea preferred transport area, or further dividing it into a land transport preferred area, a sea transport preferred area, and a land-sea transport indifference area in terms of a transport economy, respectively, $45.27 \%, 45.27 \%$, and $31.84 \%$ of the total area. We call this mirror state the ideal schema of LSTSB model.

Scenario 2: different ratios of freight rates-without considering time costs. The current ratio of freight rates of sea and land transport is $1: 4$. However, the freight rate of CRE fluctuates around $\$ 0.4-0.7 /(\mathrm{FEU} \mathrm{km})$, and was even so low as $\$ 0.1 /$ (FEU $\mathrm{km}$ ) (Wang et al., 2017). Furthermore, it is possible for this ratio to be improved through the development of land transport infrastructure. Here, we simulate the transport balance lines under different ratios, which are 1:4, 1:3 and 1:2, respectively; the result is shown in Fig. 5. With the increasing of the ratio, the transport balance line moves towards the coast. When the freight rates of land and sea transport are equal, then land transport dominates the entire semicircle.

Scenario 3: different values of a container's goods-time costs considered. In this scenario, we need to fix the values of some elements. The radius is set as $5500 \mathrm{~km}, t_{1}$ is equal to 15 days, $t_{\mathrm{s}}$ is equal to 30 days, in this case, the relative speeds of land and sea transport are quite similar to the current situation in reality. The 

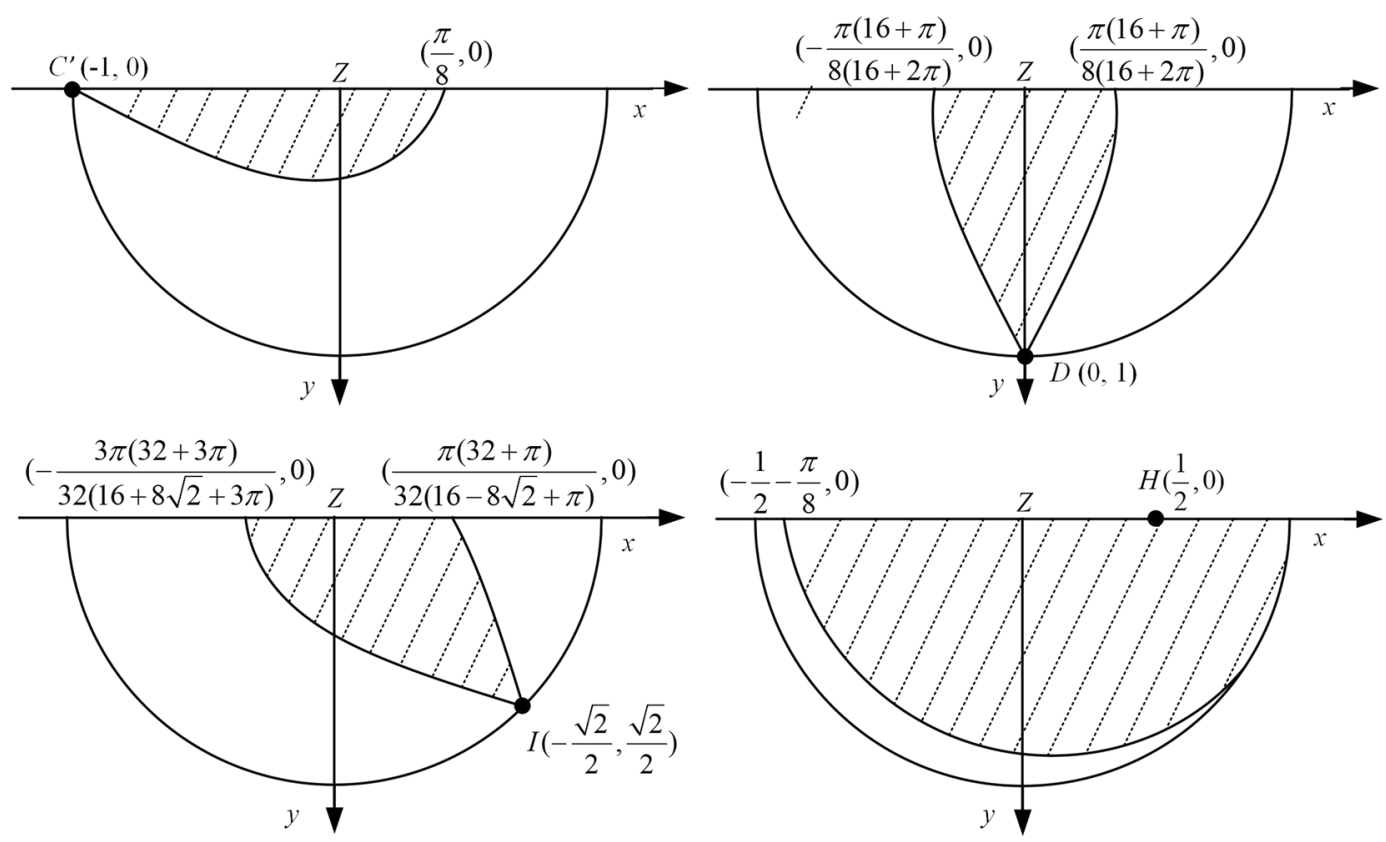

Fig. 3 Land-sea transport balance lines of different destinations

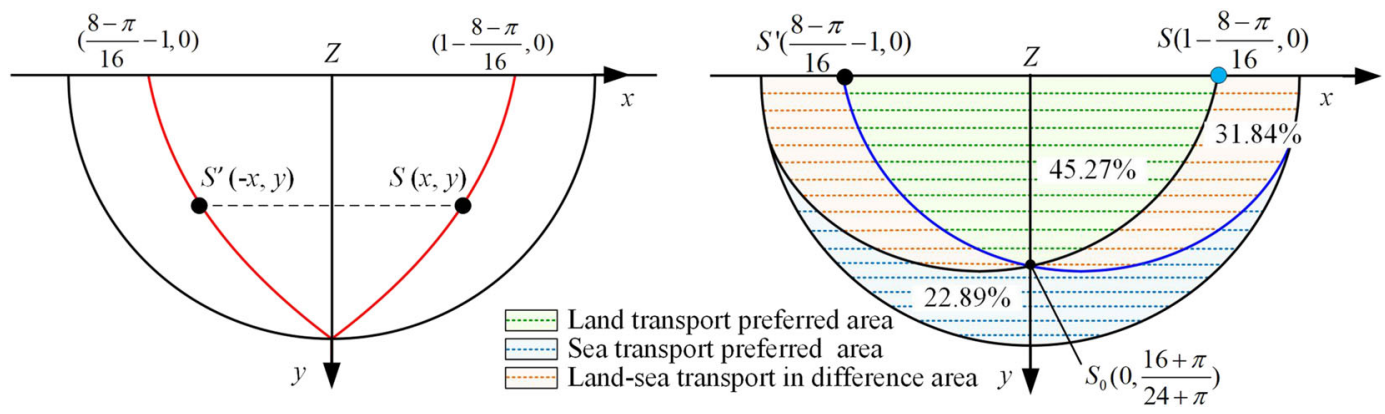

Fig. 4 Ideal schema of the LSTSB Model in Scenario 1

interest rate $i$ is $1.6 \%$ /day, and as the average value of a container's goods is about $\$ 300 \times 10^{3}$. We simulate the transport balance lines for every $\$ 300 \times 10^{3}$ increase in value.

As Fig. 6 shows, line $f$ is the transport balance line without considering time costs when $C^{\prime}$ is taken as the destination. If the value of goods in a container is $\$ 300 \times 10^{3}$, then the transport balance line $f_{3}$ extends to circumference with the land transport dominated area enlarged. The balance line moves to periphery gradually with the value increasing, like contour lines distribution. The $\$ 3000 \times 10^{3}$ contour line takes the area even near the coast on the right side of semicircle as land transport area. If a location has a definite shortage in land transport to transmit goods to a destination, it may change to a land power status when the value of goods is high because of the lower time costs of land transport.

Scenario 4: different speeds of land transport-time costs considered. The analysis of the scenarios above is based on the current speed of the CRE, which is nearly $30 \mathrm{~km} / \mathrm{h}$. However, the speed of freight rail transport is about $120 \mathrm{~km} / \mathrm{h}$ in China, and it is possible to increase this to the speed of high-speed railway in the future, which is $250-350 \mathrm{~km} / \mathrm{h}$. Thus, we put forward simulation of quicker speeds of rail transport in scenario 4. The transport balance lines of destination $C^{\prime}$ are shown in Fig. 7, taking $15,10,5$ and 2 days as $t_{1}$, respectively. If $t_{1}$ is only 2 days, which means it takes 2 days to transfer from $C$ to $C^{\prime}$ by the land bridge, the speed of rail transport is nearly $250 \mathrm{~km} / \mathrm{h}$, which can be considered as the speed of a high-speed railway. At this situation, $f_{9}$ extends to the east coast area, and it is much more economical for the whole semicircle area to choose the land transport mode when the value of goods is up to $\$ 1500 \times 10^{3}$.

\section{Case study}

Datasets. This section presents a case study of Eurasia under the BRI based on the LSTSB Model. The datasets include the railway network (from open source websites www.naturalearthdata.com/ downloads/ and www.diva-gis.org/gdata, current routes and the planning map of the CRE (National Development and Reform Commission, 2016), and the map of the main railway networks along the BRI (Liu et al., 2017)) together with maritime data consisting of shipping miles between 59 major Eurasian trade ports (from China's national shipping service website: www.cnss. com.cn/). The speeds and freight rates of land and sea transport, interest rate and the value of a container are set as same as above analysis, which are $700 \mathrm{~km} /$ day $(29.2 \mathrm{~km} / \mathrm{h})$ and $660 \mathrm{~km} /$ day $(27.5 \mathrm{~km} / \mathrm{h}), \$ 0.6 /(\mathrm{FEU} \mathrm{km})$ and $\$ 0.15 /(\mathrm{FEU} \mathrm{km}), 1.6 \%$ /day, and $\$ 300 \times 10^{3}$.

Under the BRI, Beijing is taken as one destination and the Tianjin port is taken as its nearest port to analyse the transport 


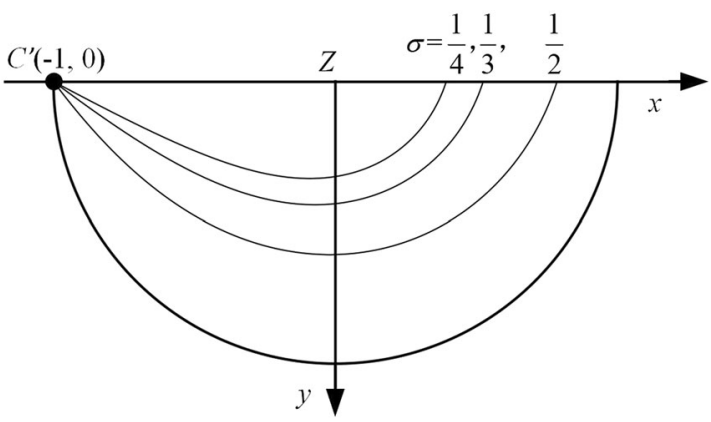

Fig. 5 Land-sea transport balance lines of different ratios of freight rates

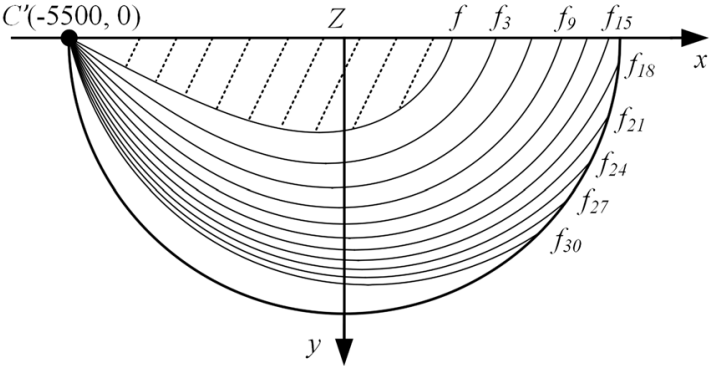

Fig. 6 Land-sea transport balance lines of different values of a container's goods

balance pattern in Eurasia. On the other side of Eurasia, as one of the three largest economies, the EU bilateral trade with China was valued at about $\$ 547.02$ billion in 2016, accounting for $14.8 \%$ of the EU import and export of goods (UNECE, 2018). China is the EU's second largest export market and its largest source of imports. Thus, choosing the EU as the western destination point is highly policy relevant. There are numerous ports in the EU forming several aggregated port areas, including Rotterdam-Amsterdam, Antwerp-Zeebrugge, Genoa-La Spezia-Savona, and so on (Notteboom, 2010). The inland logistic core area pointed to by gateway groups is the French and German area. Between them, in the EU, Germany has the largest bilateral trade volume with China. Therefore, this case study set Berlin as the destination in Europe and Rotterdam (a deep-sea port in the big gateway group Rhine-Scheldt delta nearby) as its key port. The main railway transportation network and shipping routes are shown in Fig. 8.

\section{Rail and sea transport balance line and its spatial pattern in Eurasia}

Freight costs only considered. The spatial balance line of land and sea transport in Eurasia is shown as the blue solid line in Fig. 9. The background colour is the minimum transport cost to Beijing or Berlin. Overall, the average freight cost of transporting containers to Beijing on the Eurasian continent is about $\$ 3137.58$ and $\$ 3529.90$ to Berlin. The spatial distribution of land and sea transport costs shows a clear pattern of 'low in the East and West sides' and 'high in the centre': Namely, low in the central heart of Europe and the eastern and central parts of China (land transport advantages are obvious) - high in central Russia, Central Asia, the Middle East, and Western China (both sea and land freight rates are high)-low in the Indian Ocean coast, Korean Peninsula, Japan, and other coastal regions (obvious maritime advantages). Basically, a line extends from the Russian Baltic Sea region-the Caspian Sea coast of Kazakhstan-Turkmenistan-Tajikistan-northwestern
China-Mongolia to the Russia East Siberian mountain region, which divides the Eurasian continent into a central hinterland land transport preferred area and an outer ring sea transport preferred area, the coverage ratio of these two areas is $1: 1.98$.

Specifically:

(1) land transport preferred area: this is where the rail transport freight costs of containers to Beijing and Berlin are much lower than the costs of shipping. The average freight cost of the land transport area is $\$ 2619.59$, accounting for $\sim 33.6 \%$ of the total area. The countries that are part of the land transport region mainly include Russia, Kazakhstan, Turkmenistan, and Tajikistan; all of which are far removed from the coastline.

(2) sea transport preferred area: this is where the shipping costs of transport containers to Beijing and Berlin are much lower than the costs of rail transport in this region. The average freight cost of the sea transport area is $\$ 2235.30$. The sea transport region consists of 75 countries, accounting for $\sim 66.4 \%$ of the total area. At the same time, these countries and regions happen to be far stronger economically than the land transport areas.

Time costs considered. When the time costs are added to the transportation costs, the land and sea transport balance line moves from the inland area to the coastal area. The balance line $\$ 300 \times 10^{3}$ is shown as a dotted blue line in Fig. 9. In this case, the land transport advantage area expands significantly and the expansion of the West is more obvious than the East. The land and sea transport balance line extends from Berlin, Germany-the north shore of the black sea-the south of Caspian Sea-Turkey-the Qinghai-Tibet plateau-Baoji, China-Greater Khingan Mountains to Chumikan, Russia. Maritime transport still has the absolute advantage in most of Northwest China, the Euro Atlantic area, the Mediterranean, the Middle East, and Southeast Asia. The centre of the Eurasia land area and the outer sea area form a 1.1:1 balanced competitive situation in transportation, that is, generally, the hinterland in Eurasia has a relative advantage for the transport of containers to East Asia and the EU mainland by rail.

Specifically:

(1) land transport preferred area: where the total costs of transport containers by rail to Beijing and Berlin are much lower than the costs of shipping. The average cost of the land transport area is $\$ 2546.39$, accounting for $\sim 52.4 \%$ of the total area. The countries that are in the land transport region expand to East and North Europe according to the line without considering time costs.

(2) sea transport preferred area: the total costs of transport containers to Beijing and Berlin by shipping are much lower than the costs by rail in this region. The average cost of the sea transport area is $\$ 2476.80$, with a decreased area ratio of $47.6 \%$. The sea transport region consists of 62 countries. For example, when considering only the basic freight rates, these cities are all in the sea transport area. However, after considering the time spent, the costs of land and sea transport change. For example, with Berlin as the end point, Lanzhou's land transport cost is \$4921.38, and the sea transport cost increases from $\$ 4433.86$ to $\$ 5482.81$. When Beijing is the destination, Moscow's land transport cost is $\$ 4282.15$ and the shipping cost is $\$ 3801.38$. Due to the time spent in sea transport, which is about 28 days longer than land transport, the interest income accumulated during the time spent, increases the cost of sea transportation to \$5155.64, which changes the predominant position of maritime transport.

Spatial partition of the land and sea transport balance in Eurasia. In fact, space competition or space balance is an issue, not only in economic geography but also in geopolitics. Mahan 


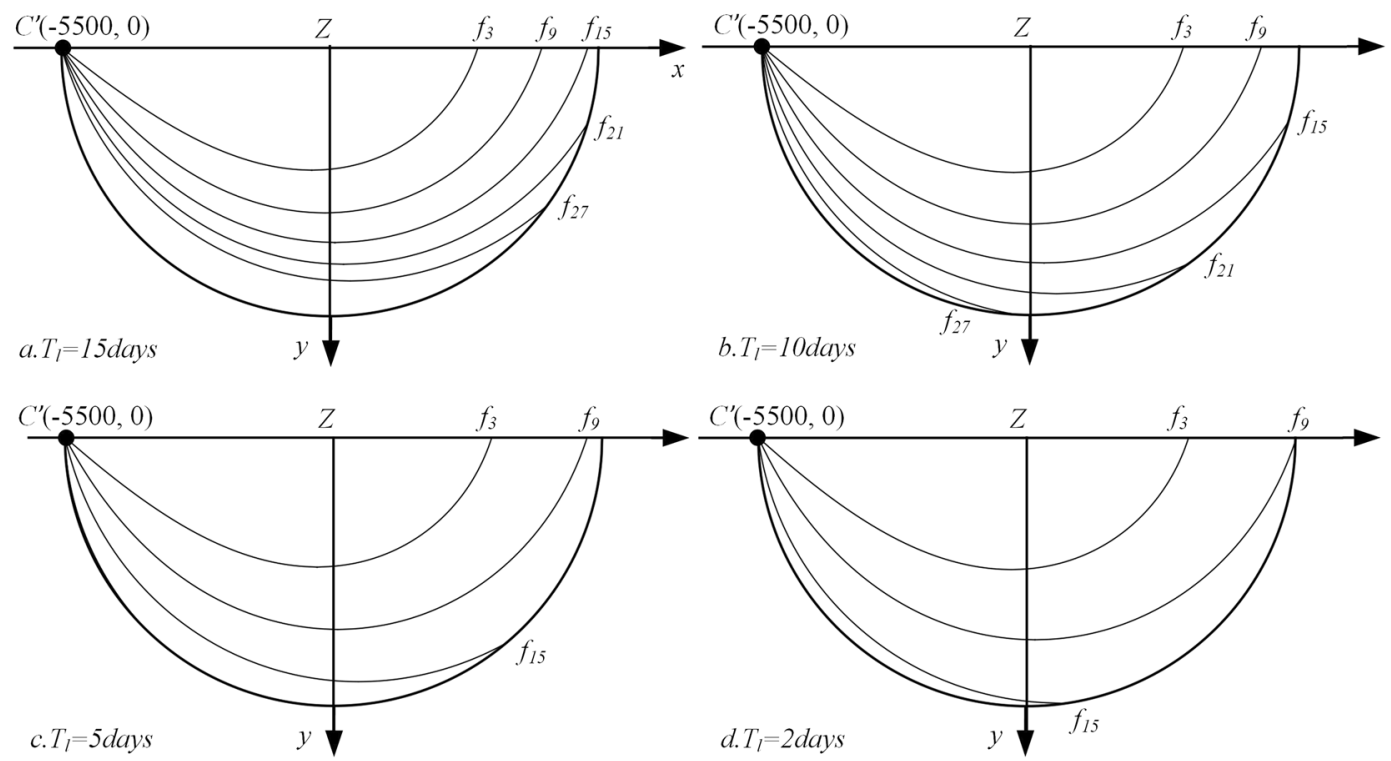

Fig. 7 Land-sea transport balance lines of different speeds of land transport

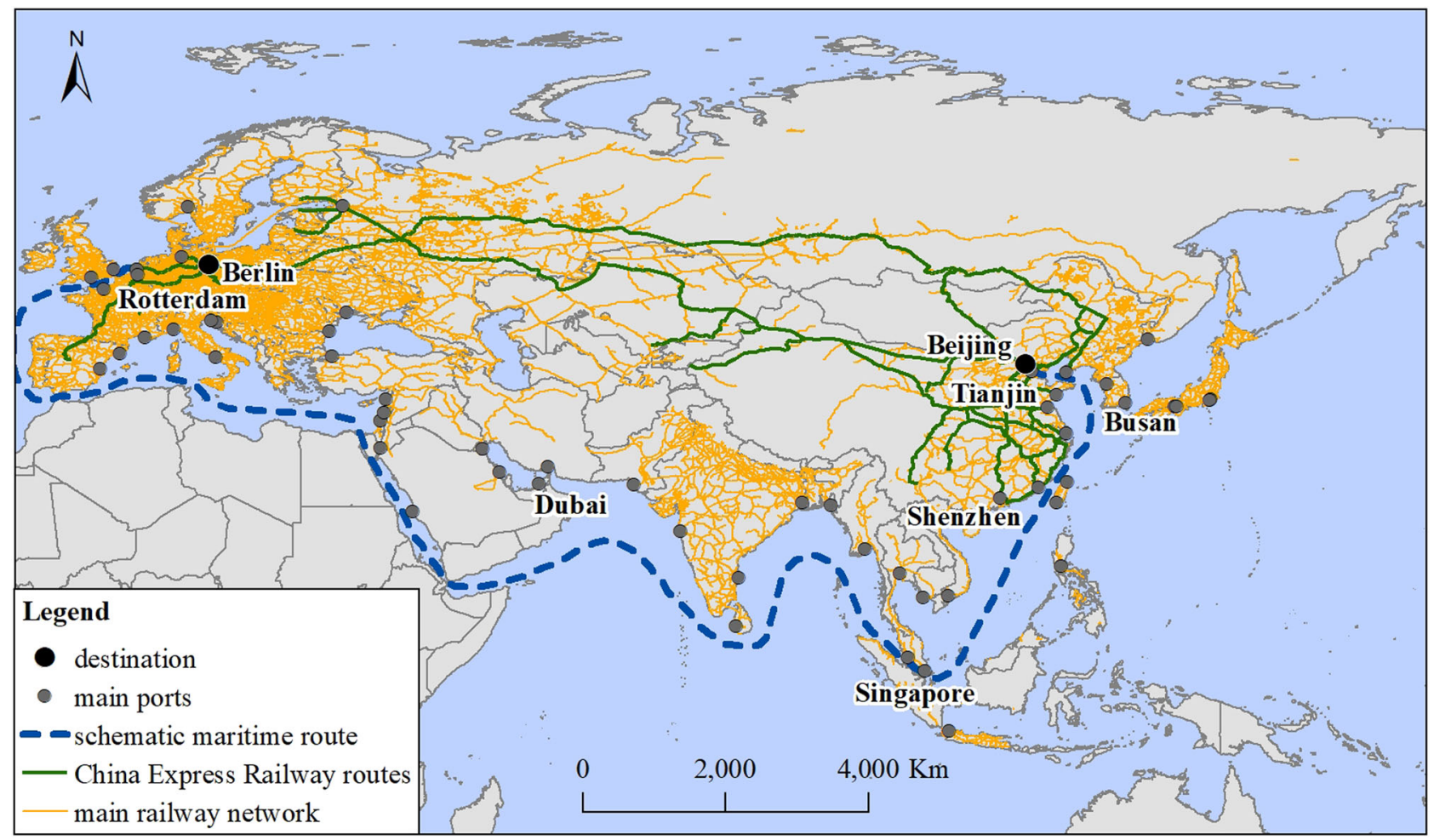

Fig. 8 Main railway and maritime transport routes in Eurasia

(2013) put forward his Sea Power Theory in 1890. He thought that because the ocean occupies three-quarters of the earth's surface, any country or union that could control the high seas could rule the world. However, it is hard to rule Eurasia by controlling key nodes on the sea routes because of its large land area. Thus, Sir Halford Mackinder (Mackinder, 2014) formulated the Heartland Theory and successively demarcated Eurasia three times. In his 1904 essay, he identified Eastern Europe and North Asia as the world heartland area. Then, in 1919, Tibet China and Mongolia, as well as the area surrounded by the Baltic Sea and the Black Sea, were added to his pivot region. In 1943, he drew a line extending from the northwestern border of China to the central part of the former Soviet Union, outlined as an area similar to the shape of a heart. Subsequently, Spykman (Spykman, 1944; Gray, 2015) proposed the Rimland Theory. He divided Eurasia into heart zones, rimland, and outlying areas (offshore continents and islands). $\mathrm{He}$ believed that threats to sea power countries were not in the heart zone of Eurasia but rather in the rimland between the heart zone and the coastal zone, and the status of this area would continue to rise in the future, becoming a key area for ruling the coastal zone. 


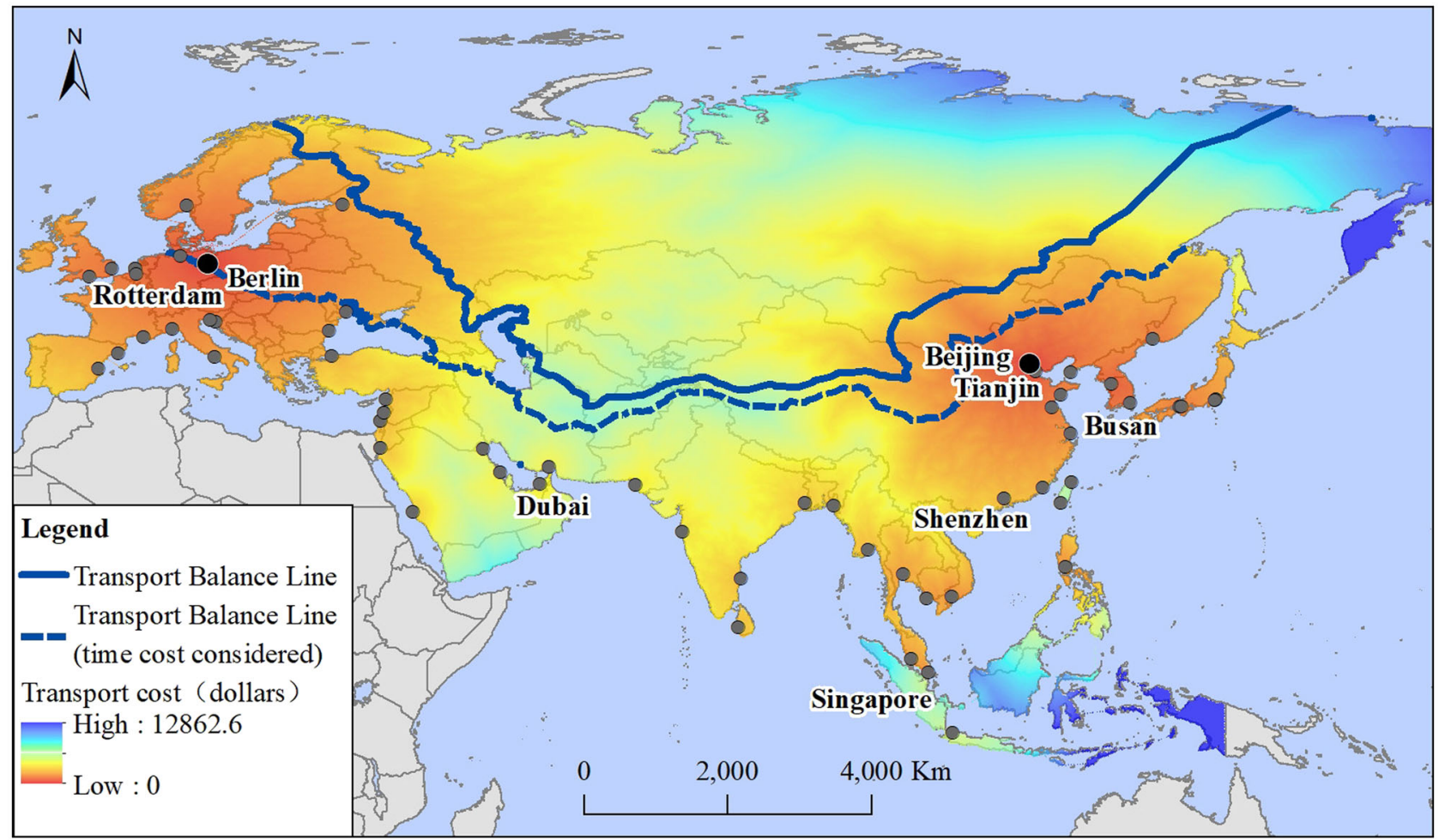

Fig. 9 The transport balance lines in Eurasia. (Note: As the calculations of costs are all based on distances in the model, we use the Equidistant Conic Projection (a common equal distance projection) (Goode, 1925) in the calculation process and the Goode Homolosine Projection (equal-area projections) (Snyder, 1978) for area statistics.)

In our analysis, the land and sea transport balance line of Eurasia is highly consistent with the boundary lines of the Mackinder and Spykman theories. Although there are different understandings of the outer area and sea transport preferred area partitions, this general consistency indicates that an analysis of transport spatial balance can bring a new analytic perspective to geopolitics and geo-economics on the Eurasian continent. According to the theories of sea and land power in geopolitics and the spatial balance lines of transport, we can partition Eurasia into organisational divisions (Fig. 10). One division is the inland area or called the land transport preferred area, including a major part of Russia, middle Asia, and some parts of China. A second division is the sea area or called the sea transport preferred area, including the Middle East, South Asia, Southeast Asia, Japan, and Korea. The third division is the land-sea area or called the land and sea transport indifference area, covering a major part of China (except for Xinjiang, Qinghai, Tibet, Ningxia, and Inner Mongolia, the dividing line is consistent with China's $400 \mathrm{~mm}$ precipitation line and traditional agrarian line or so-called $\mathrm{Hu}$ Huanyong line), as well as the European mainland, the Murmansk, Leningrad Region, the Pskov Region in the Federal District of northwestern Russia and the Khabarovsk Krai, Primorsky Krai, and the Jewish Autonomous Region in the far east region.

From the perspective of the connection between transport and globalisation, the development of Eurasia could be divided into three stages, two past and one future. The first stage is the ancient land transport period, which can be called globalisation era 1.0. The ancient silk road was the symbol of this era. The second stage is the modern maritime transport period, which is the so-called globalisation era 2.0. In this period, sea transport has almost completely replaced land transport on a global scale. At present, $85 \%$ of global trade is completed by sea journey. One of the inevitable results caused by this ratio is the imbalance in the economy between non-littoral areas and littoral areas. It may be argued that this is a major problem for globalisation era 2.0. From the perspective of this study, we find that the BRI is trying to rediscover relative advantages of land transport and create new growth opportunities for globalisation in order to further the integration of Eurasia and enter the third globalisation era, the era of 3.0, based on joint land-sea transport.

\section{Conclusion}

In the future, the BRI will be significant to the integration of economic trade in Eurasia, following the premise that land and sea transport should find a spatial balance. In fact, analysis of the competition and cooperation between land and sea transport can also be of theoretical significance for transport geography. This paper presents a LSTSB model based on the conceptualised Eurasia and simulates different land-sea transport scenarios. We then identify the transport balance lines by applying the model to Eurasia and present the partition of land and sea transport dominated areas in line with the theories of geopolitics.

The main insights are as follows:

Four scenarios based on different locations of destination, different freight costs, different values of a container's goods and different speeds of transport are simulated using the theoretical model. They show that these basic factors influence the spatial balance lines of transportation. The results indicate that land transport is relatively competitive with sea transport but that this depends on different factors. Land transport may be undervalued at present due to long-term cooperation behaviour between governments or enterprises with maritime companies.

The case study shows that in terms of freight costs, maritime transport has an obvious advantage in Eurasia. The transport spatial balance line divides the Eurasian continent into a land and sea transport competitive pattern with an area ratio of 1:2. 


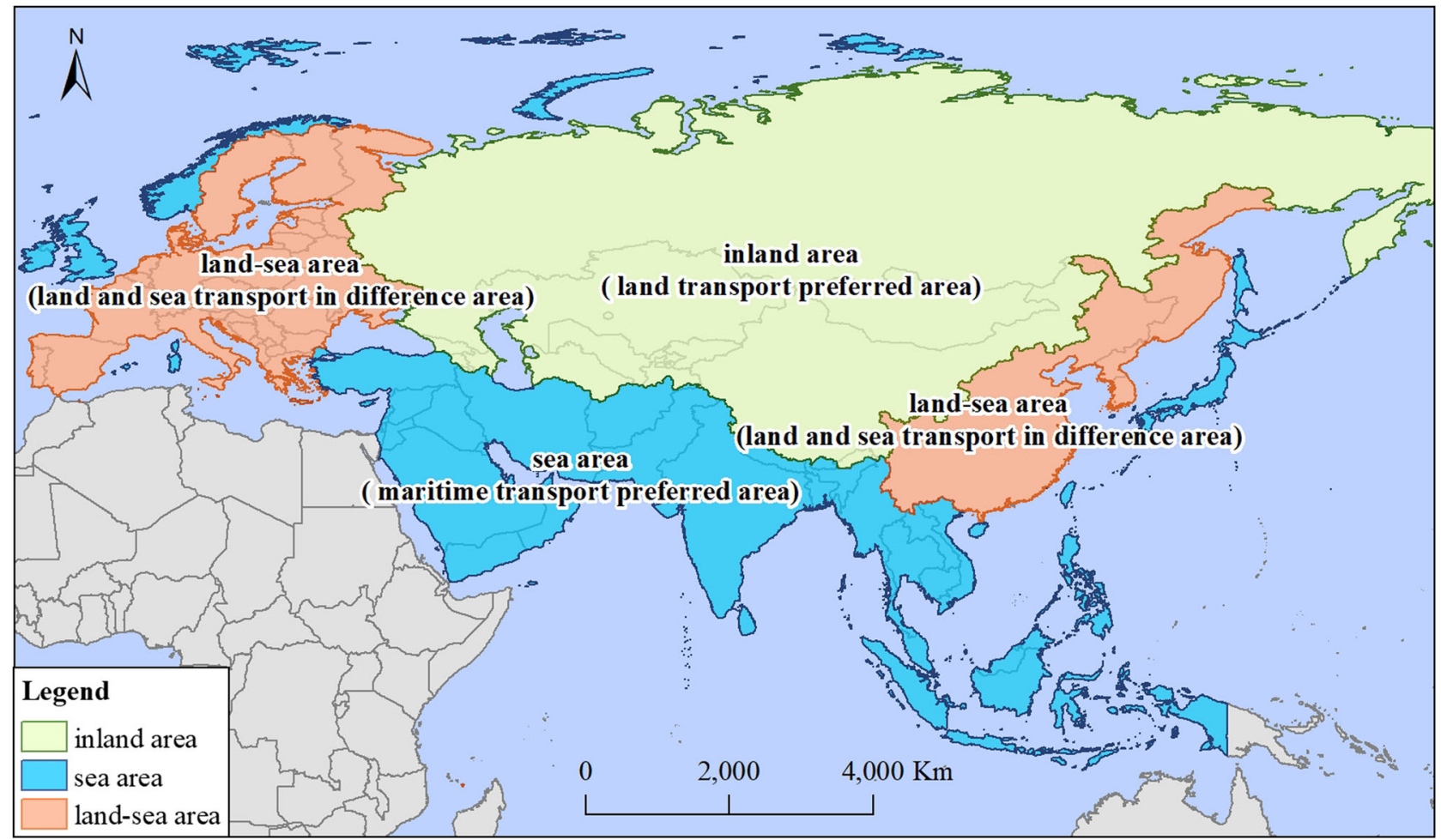

Fig. 10 Comprehensive partition of Europe-Asia under geo-economics and geopolitics. (Note: Although the result is mostly reliant on the rail network, "rail transport preferred area" is named as "land transport preferred area" here to match the discussion with the classic land and sea power theories.)

However, this ratio changes to $1: 1$ when we take time costs into consideration. Results show that the Economic Belt on road has economic feasibility and rationality.

Furthermore, the spatially competitive pattern of land-sea transport in Eurasia is highly consistent with geopolitical theories. This paper presents a partition of transport areas based on the calculation of balance lines, showing the land transport preferred area, the sea transport preferred area and the land-sea transport indifference area. The partition shows that the China-Russia-EU region, located in the land transport preferred area and the land-sea transport indifference area, is the key pivot area of integration influencing the current economic geographic imbalance in Eurasia. Further, it can serve as the analytic basis underpinning the necessity of increasing cooperation between China and the EU under the BRI, which is in the land-sea indifference area. Thus, the LSTSB model can bring a new perspective to the discussion of the spatial pattern of geopolitics and geo-economics in Eurasia.

\section{Discussion}

The analysis of the factors and the construction of the LSTSB model reflect the variability of the transport spatial competitive pattern. We only consider four scenarios of different factors and their influence within the theoretic model. Scenarios of superposition can, however, be simulated in further studies, where some or all the factors change at once, in order to meet the needs of projects, planning and policy. Furthermore, we need to recognise that the assumption of only using interest income as the time cost has a certain influence on the results. Whether the value of time can be estimated by the economic benefits equivalent to interest income needs to be studied further. In addition, different types of goods are different in their sensitivity to time. The number of containers reflects the scale and level of transportation directly and can also represent the interactive intensity of physical trade. Furthermore, many local governments and companies have stated that their prices for railway transport would be much lower if the number of containers increased (The Paper News, 2015). In this case, the number of containers should form part of the model by finding its relationship with transport cost per unit through some survey datasets. However, this paper only presents a preliminary exploratory analysis in this field, the spatial competition between land and sea transport needs to be interpreted in a more accurate way from the perspective of the economic efficiency of transportation.

There are some limitations in the case study too. First, it is based on the precondition of using Beijing and Berlin as the destinations, and the current fluctuated values of speeds, goods and freight rates are all set unique. According to the simulation under different scenarios, preferential policies for transportation could be carried out by governments or transport companies in different places, which could further strengthen the practicality of our model. Specifically, some countries (such as India) oppose China's BRI (Blah, 2018; Pattanaik, 2018). Therefore, we could add evaluations of the strategies for infrastructure construction, of such countries, in the future. Second, container transportation is a complex process. The extent to which the cross-border transportation between countries is frictionless will affect the land transport pattern. Moreover, these factors are difficult to quantify and have not been considered in this paper, such as unequal freight cost rates in different countries, different capabilities and widths of rails, time spent at ports, tariffs, insurance costs and so on, which may also influence actual costs. Third, in not considering the road network, this paper presents a basic possible pattern of land and sea transport balance based on the current railway and maritime networks, which may bias our results. At a strategic level, the results can offer positive suggestions to influence a better approach for transportation. It will, however, be necessary for individual decision-makers to make accurate 
calculations of the costs of different routes at a micro-level. Additionally, container shipping on the northern sea route is a potential transport corridor (Verny and Grigentin, 2009), it could be included in the future study. Moreover, because of the organisational system and mature development of transport companies, the related data of container transport are easy to obtain, which helps determining the costs and speeds more easily. In contrast, it is hardly to collect datasets of bulk transport. However, the effect of bulk transport may be significant because it is likely to form a large proportion of global maritime trade (J.P. Morgan Asset Management, 2019). This may render some ports more economically viable. Further, for both ports and rail connections there may be capacity issues. An analysis which considers multiple origins and destinations and alternative route assignments and capacity constraints would be of relevance in considering the development of infrastructure to support the BRI. Further work is needed on the cooperative integration between land and sea transport in Eurasia as this analysis has concentrated on the more competitive aspects.

\section{Data availability}

All data analysed and generated are included in the paper.

Received: 16 May 2019; Accepted: 24 September 2019;

Published online: 15 October 2019

\section{Notes}

1 The sea tariff is set as $0.15 \$ /(F E U ~ k m)$ based on the current rates from different shipping companies' services between China and Europe (Mo et al., 2015). Rail tariffs differ from $0.4 \$-0.7 \$ /(\mathrm{FEU} \mathrm{km})$ in different countries and routes, here we choose 0.6 $\$ /($ FEU km) which is a medium rate of CRE (Wang et al., 2018).

2 It takes 16 days from Chongqing, China to Duisburg, Germany by CRE, the distance is $11,179 \mathrm{~km}$. Here we take the average speed of it as rail speed in Eurasia, which is $29.2 \mathrm{~km} /$ h. It can be taken as the speed of CRE in the initial development era. The average speed can be possibly faster in the future. According to the current average maritime speed, which is nearly $15 \mathrm{knots}(\approx 27.8 \mathrm{~km} / \mathrm{h}$ ) (from https://worldoceanreview.com/en/wor-1/ transport/global-shipping/2/), here we set speed of shipping at $27.5 \mathrm{~km} / \mathrm{h}$.

3 The benchmark interest rate in China was last recorded at $4.35 \%$ in 2015 , while it was 6\% before 2014 (from https://tradingeconomics.com/ china/interest-rate), and currently larger deposits can get about $6 \%$ interest rate from banks.

\section{References}

Blah M (2018) China's Belt and Road Initiative and India's concerns. Strateg Anal 42:313-332

Blauwens G, Van De Voorde E (1988) The valuation of time savings in commodity transport. Int J Trans Econ/Riv Int Econ Trasp 15:77-87

Chen D, Yang Z (2018) Systematic optimization of port clusters along the Maritime Silk Road in the context of industry transfer and production capacity constraints. Transp Res Part E 109:174-189

Ferdinand P (2016) Westward ho-the China dream and 'one belt, one road': Chinese foreign policy under Xi Jinping. Int Aff 92:941-957

Goode JP (1925) The Homolosine projection: a new device for portraying the Earth's surface entire. Ann Assoc Am Geogr 15:119-125

Gray CS (2015) Nicholas John Spykman, the balance of power, and international order. J Strateg Stud 38:873-897

Hillman JE (2018) The rise of China-Europe railways [Online]. https://www.csis. org/analysis/rise-china-europe-railways

Hummels D (2007) Transportation costs and international trade in the second era of globalization. J Econ Perspect 21:131-154

Islam D, Zunder T, Jackson R, Nesterova N, Burgess A (2013) The potential of alternative rail freight transport corridors between Central Europe and China. Transport Probl 8:45-57

J.P. Morgan Asset Management (2019) 2019 Global alternatives outlook [Online]. https://am.jpmorgan.com/us/institutional/2019-alternatives-transport

Jiang Y, Sheu J-B, Peng Z, Yu B (2018) Hinterland patterns of China Railway (CR) express in China under the Belt and Road Initiative: a preliminary analysis. Transp Res Part E 119:189-201
Krugman P (1993) Geography and trade. MIT Press

Lam JSL, Cullinane KPB, Lee PT-W (2018) The 21st-century Maritime Silk Road: challenges and opportunities for transport management and practice. Taylor \& Francis

Lee PT-W, Hu Z-H, Lee S-J, Choi K-S, Shin S-H (2018) Research trends and agenda on the Belt and Road (B\&R) initiative with a focus on maritime transport. Marit Policy Manag 45:282-300

Liu W, Dunford M (2016) Inclusive globalization: unpacking China's belt and road initiative. Area Dev Policy 1:323-340

Liu W, Dunford M, Gao B (2018) A discursive construction of the Belt and Road Initiative: from neo-liberal to inclusive globalization. J Geogr Sci 28:1199-1214

Liu W, Tian J, Ou X (2017) Research of the belt and road initiative. The Commercial Press, Beijing

Mackinder HJ (2014)The geographical pivot of history. Geopolitics. Routledge

Mahan AT (2013)The influence of sea power upon history, 1660-1783. Read Books Ltd

Mo H, Wang J, Song Z (2015) Economically suitable areas of China's transnational container transport by land in the Silk Road Economic Belt. Prog Geogr 34:581-588

National Development and reform commission (2016) Planning of China Railway Express construction (2016-2020) [Online]. http://www.ndrc.gov.cn/gzdt/ 201610/P020161017544178660107.pdf

National development and reform, Commission ministry of foreign, Affairs ministry of commerce of China (2015) Vision and actions on jointly building Silk Road economic belt and 21st century maritime Silk Road. Foreign Languages Press [Online], Beijing

Notteboom TE (2010) Concentration and the formation of multi-port gateway regions in the European container port system: an update. J Transp Geogr 18:567-583

Pattanaik SS (2018) Analysing China's soft power strategy and comparative Indian initiatives. Strateg Anal 42:456-458

Peng P, Yang Y, Lu F, Cheng S, Mou N, Yang R (2018) Modelling the competitiveness of the ports along the Maritime Silk Road with big data. Transp Res Part A 118:852-867

Rodemann H, Templar S (2014) The enablers and inhibitors of intermodal rail freight between Asia and Europe. J Rail Transp Plan Manag 4:70-86

Schramm H-J, Zhang X (2018) Eurasian rail freight in the one belt one road era. In: Stentoft J (ed) 30th Annual Nofoma Conference. Syddansk Universitet Institut for Entreprenørskab og Relationsledelse

Scotchmer S, Thisse J-F (1992) Space and competition. Ann Reg Sci 26:269-286

Snyder JP (1978) Equidistant conic map projections. Ann Assoc Am Geogr 68:373-383

Spykman NJ (1944) The Geography of the peace. Harcourt Brace and Company

Swaine MD (2015) Chinese views and commentary on the 'One Belt, One Road' initiative. China Leadersh Monit 47:3

Tavasszy L, Minderhoud M, Perrin J-F, Notteboom T (2011) A strategic network choice model for global container flows: specification, estimation and application. J Transp Geogr 19:1163-1172

The Paper News (2015) Huang Qifan: the rise code of Chongqing [Online]. The Paper News. http://www.thepaper.cn/newsDetail_forward_1370094

Tsuji H (2009) The global financial crisis and Trans-Siberian railway transportation. Transit 29(3):548

UNECE (2018) Report on Phase III of the Euro-Asian Transport Links Project

UNECE/UNESCAP (2008) Joint study on developing Euro-Asian transport linkages

Verny J, Grigentin C (2009) Container shipping on the northern sea route. Int J Prod Econ 122:107-117

Wang J, Jiao J, Ma L (2018) An organizational model and border port hinterlands for the China-Europe Railway Express. J Geogr Sci 28:1275-1287

Wang J, Jing Y, Wang C (2017) Study on better organization of China-Europe Express Train. Bull Chin Acad Sci 32:370-376

Wang Y (2016) Offensive for defensive: the belt and road initiative and China's new grand strategy. Pac Rev 29:455-463

Wang Z, Dong S, Li Z, Li Y, Li J, Cheng H (2015) Traffic patterns in the Silk Road Economic Belt and construction modes for a traffic economic belt across continental plates. J Resour Ecol 6:79-86

Xinhuanet (2017) China Express Railway have run 6235 trains and connected to 12 countries and 34 cities in Europe [Online]. http://www.xinhuanet.com/ politics/2017-12/26/c_129775909.htm

\section{Acknowledgements}

This work is supported by the National Natural Science Foundation of China (Gran Nos. 41430635 and 41701122). The authors gratefully thank Professor Michael Batty (Centre for Advanced Spatial Analysis, UCL) for his suggestions on the manuscript. 


\section{Competing interests}

The authors declare no competing interests.

\section{Additional information}

Correspondence and requests for materials should be addressed to Y.C.

Reprints and permission information is available at http://www.nature.com/reprints

Publisher's note Springer Nature remains neutral with regard to jurisdictional claims in published maps and institutional affiliations. (c) (i) Open Access This article is licensed under a Creative Commons Attribution 4.0 International License, which permits use, sharing, adaptation, distribution and reproduction in any medium or format, as long as you give appropriate credit to the original author(s) and the source, provide a link to the Creative Commons license, and indicate if changes were made. The images or other third party material in this article are included in the article's Creative Commons license, unless indicated otherwise in a credit line to the material. If material is not included in the article's Creative Commons license and your intended use is not permitted by statutory regulation or exceeds the permitted use, you will need to obtain permission directly from the copyright holder. To view a copy of this license, visit http://creativecommons.org/ licenses/by/4.0/.

(C) The Author(s) 2019 